\title{
A Importância da Realização Precoce do Teste do Pezinho: O Papel do Enfermeiro na Orientação da Triagem Neonatal
}

\author{
Eva Fernandes Oliveira ${ }^{1}$; Anderson Pereira Souza ${ }^{2}$
}

Resumo: Popularmente chamado de "teste do pezinho", a triagem neonatal (TN) é um exame de rastreamento feito nos recém-nascidos (RN). Este é feito através da coleta sanguínea em papel-filtro na região do calcanhar do $\mathrm{RN}$, por ser esta área bastante vascularizada. O período adequado para a coleta não deve ser inferior a 48 horas de amamentação do bebê. Constituindo um período ideal entre o $3^{\circ}$ e o $7^{\circ}$ dia de vida do RN. O principal objetivo do "teste do pezinho" é buscar identificar precocemente as doenças do metabolismo, antes mesmo que estas patologias comecem a apresentar os primeiros sinais e sintomas, proporcionando assim aos RN's uma melhor qualidade de vida. As doenças preconizadas pelo Ministério da Saúde (MS) que são rastreadas através do "teste do pezinho" padrão são: fenilcetonúria, Hipotireoidismo congênito, Anemia falciforme (e outras hemoglobinopatias) e a Fibrose cística. Esta pesquisa bibliográfica tem como base metodológica características exploratórias, descritivas, qualitativas e teve como objetivo geral de verificar a importância da realização precoce do teste do pezinho. Os resultados nos mostram o enfermeiro que tem contato direto com a gestante durante o pré-natal deve enfatizar quanto às orientações sobre a importância da realização do "teste do pezinho", devido sua grande importância.

Palavras-chave: Teste do Pezinho, Recém nascidos. Precoce.

\section{The Importance of Early Realization of Guthrie Test: The Role of the Nurse in the Neonatal Screening Guidance}

\begin{abstract}
Popularly called the "foot test", neonatal screening (TN) is a screening test done on newborns (RN). This is done through blood collection on filter paper in the region of the heel of the RN, because this area is quite vascularized. The appropriate period for collection should not be less than 48 hours of breastfeeding of the baby. It is an ideal period between the 3rd and 7th day of life of the RN. The main objective of the "test of the foot" is to try to identify early metabolic diseases, even before these pathologies begin to present the first signs and symptoms, thus giving the NBs a better quality of life. The diseases advocated by the Ministry of Health (MS) that are screened through the standard "foot test" are: phenylketonuria, congenital hypothyroidism, sickle cell anemia (and other hemoglobinopathies), and cystic fibrosis. This bibliographic research has a methodological basis exploratory, descriptive and qualitative characteristics and had as general objective to verify the importance of the early performance of the test of the foot. The results show us that the nurse who has direct contact with the pregnant woman during prenatal care should emphasize the importance of performing the "test of the little foot" because of its great importance.
\end{abstract}

Keywords: Test of the Foot, Newborn. Precocious.

\section{Introdução}

A palavra triagem para a saúde pública significa a execução primária de exames que são realizados em uma população que apresenta alguma chance de desenvolver alguma patologia (GARCIA; FERREIRA; OLIVEIRA, 2007).

\footnotetext{
${ }^{1}$ Curso de enfermagem da Faculdade Independente do Nordeste Campus Vitória da Conquista.

Autor Correspondente: evatec.fernandes@hotmail.com;

2 Mestre em Patologia Humana pela UFBA/FIOCRUZ. Professor Assistente de Fisiologia Humana no curso de medicina da UESB Universidade Estadual do Sudoeste da Bahia-Campus de Vitória da Conquista Bahia. Professor de Fisiologia Humana, Patologia Geral e Biologia Geral na FAINOR - Faculdade Independente do Nordeste em Vitória da Conquista - BA.
} 
Popularmente chamado de "teste do pezinho", a triagem neonatal (TN) é uma exame de rastreamento feito nos recém-nascidos (RN) (LEITE; PONTES, 2009).

Este exame é feito através da retirada de sangue do calcanhar do RN, pois esta área é considerada bastante vascularizada e em seguida é realizada a coleta do sangue no papel-filtro. O momento adequado para a coleta não deve ser menor que 48 horas de alimentação do RN, constituindo um período ideal entre o $3^{\circ}$ e o $7^{\circ}$ dia de vida do RN (SANTOS et al., 2011).

O principal objetivo do TP é identificar as doenças do metabolismo, antes mesmo que estas comecem a manifestar os primeiros sinais e sintomas, proporcionando assim aos RN's uma melhor qualidade de vida. E é válido acrescer que os estudos sobre o teste do pezinho tiveram início entre meados da década de 50, entretanto, os Programas de Triagem Neonatal começaram a ser instalados em diversos países somente na década de 60 (ALMEIDA et al., 2006). No Brasil, na década de 70 a APAE (Associação de Pais e Amigos dos Excepcionais) de São Paulo, iniciou os primeiros diagnósticos para a fenilcetonúria, e em seguida, no ano de 1980, passou a diagnosticar mais outra doença que foi o hipotireoidismo congênito (BRASIL, 2002).

Estabelecendo assim por meio da portaria de no 22 do ano de 1992 que determinou a obrigatoriedade para o programa de diagnóstico precoce da fenilcetonúria e do hipotireoidismo congênito em todo o território brasileiro (BRASIL, 2001).

As doenças preconizadas pelo Ministério da Saúde (MS) que são rastreadas através do "teste do pezinho" padrão são a fenilcetonúria, Hipotireoidismo congênito, Anemia falciforme (e outras hemoglobinopatias) e a Fibrose cística (ALVES; ZAMBRANO, 2011).

Diante dessas explanações, o objetivo geral deste estudo é verificar a importância da realização precoce do teste do pezinho: o papel do enfermeiro na orientação da triagem neonatal e como justificativa nota-se que tal discussão é salutar devido ao fato de que ao realizar precocemente o teste do pezinho em RN, poder-se-á identificar as doenças do metabolismo, antes mesmo que estas comecem a manifestar os primeiros sinais e sintomas.

\section{Metodologia}

A pesquisa bibliográfica abrange um levantamento, seleção e documentação de toda bibliografia já publicada sobre o assunto pesquisado. Conforme preleciona Gil (2008, p. 44), 
“este tipo de pesquisa é desenvolvida através de fontes já existentes ou publicadas”, logo, visa proporcionar uma melhor visão deste ou torná-lo mais específico, considerando que estes são amplos e pouco esclarecidos.

Assim, este estudo é do tipo bibliográfico-descritivo, realizado por meio de uma pesquisa desenvolvida com base em material já elaborado por outros autores, disponíveis na literatura, na forma de publicações de artigos científicos publicados em periódicos.

Diante disso, busca-se fazer sobretudo um estudo onde foram selecionados artigos científicos publicados, empregando como base teórica artigos de revistas científicas que estavam disponíveis na bases de dados do Scientific Eletronic Library Online- SciELO, BVS (Biblioteca Virtual em Saúde), SCIELO (Scientific Electronic Library Online), LILACS (Literatura Latino-Americana e do Caribe em Ciências da Saúde) e PubMed (base de dados do MEDLINE).

Os critérios de inclusão para o trabalho foram: artigos primários e de revisão e prospectivos publicados nos idiomas inglês e português. Sendo assim dos 30 artigos e leis analisadas, foram utilizados 25 (vinte e cinco) ao final, como base de dados para a pesquisa. Os artigos científicos são datados de 2006 a 2017.

Os resultados e discussões foram distribuídos em eixos temáticos conforme o tema, organizados para melhor entendimento do assunto.

\section{Resultados e Discussões}

\section{Histórico}

Para a saúde pública, a palavra triar denota identificar, dentro de uma população considerada "normal", indivíduos que apresentam algum tipo de risco em desenvolver determinada patologia e que se favoreceram através de uma investigação adicional para confirmar ou eliminar este risco e de ação preventiva e terapêutica eficaz (ALVES; ZAMBRANO, 2011).

O procedimento para o teste da Triagem Neonatal (TN) foi empregado pela primeira vez no Reino Unido ao fim da década de 50, com o propósito de rastrear patologias metabólicas 
identificadas por meio da análise da urina, apenas para a identificação precoce da fenilcetonúria. Já o rastreamento neonatal feito por meio de níveis identificados no plasma sanguíneo surgiu nos EUA, em meados da década de 60, através de pesquisas feitas pelo microbiologista Robert Guthrie (RODRIGUES et al., 2010).

Guthrie, em 1963, desenvolveu um método diagnóstico para fenilcetonúria, mais simples e que gerava menos custos, através do uso do sangue de pacientes com retardo mental, coletados em papel filtro (SILVA, 2012).

Em 1965, cerca de 400.000 mil crianças foram examinadas e aproximadamente 39 evidenciavam diagnóstico de caráter positivo para a fenilcetonúria, com taxa de incidência para 1:10.000 RN. Ao decorrer dos anos, alguns estados do território americano já haviam instituído à obrigatoriedade quanto à realização do teste de triagem neonatal nos RN's. Por volta da década de 60, a Organização mundial de saúde, por seus constituintes de normas regulamentadoras constituiu o quanto é importante realizar Programas de Triagem Neonatal (PTN), principalmente em países que estão em processo de desenvolvimento, baseados em critérios obrigatórios (SILVA, 2008).

A partir do ano de 1976, o Brasil passou a realizar em São Paulo o PTN, que a princípio diagnosticava a fenilcetonúria. Depois, na década de 80 , foi incluído no exame da TN a identificação do hipotireoidismo congênito. Foi apenas nesta década que começou a possuir o amparo legal para a realização do Programa de Triagem Neonatal em algumas regiões do Brasil, que deram início de forma autônoma seus programas. Algumas destas regiões chegarão a ter legislações próprias (ALMEIDA et al., 2006).

Em São Paulo, foi inserido na APAE pelo médico Dr. Benjamin Schmidt um laboratório com o propósito de realizar maiores pesquisas para a fenilcetonúria. Este laboratório foi o primeiro a propagar o TP no Brasil e em todas as regiões da América Latina, sendo que hoje este é considerado um dos maiores laboratórios do mundo para este segmento, fazendo exames para aproximadamente 300.000 crianças por ano (SILVA, 2012).

No ano de 1990, a Lei 8069 do Estatuto da Criança e do Adolescente definiu que todos os estabelecimentos que prestassem atenção à gestante deveriam ofertar exames de triagem tendo em vista o diagnóstico e tratamento de alterações no metabolismo dos recém-nascidos, além de prestar todas as devidas orientações aos pais (SANTOS et al., 2011). 
Em seguida, estabeleceu a portaria de $n^{\circ} 822$ de junho de 2001, onde propôs a ampliação do número de patologias triadas pelo Programa Nacional de Triagem Neonatal, com o intuito de cobrir $100 \%$ dos nascidos vivos tendo como objetivo diminuir os danos e números de mortalidade dos RN's triados (BRASIL, 2002).

Esta medida enfatiza um dos princípios básicos do Sistema Único de Saúde (SUS) que é garantir acesso igualitário a todos os recém-nascidos brasileiros, independentemente de idade, raça, classe social ou origem geográfica (SALLES; SANTOS, 2009). Neste mesmo ano, o PTN (Programa de Triagem Neonatal) foi expandido para todo o território nacional (ALMEIDA et al., 2006).

\section{Teste do Pezinho: Triagem Neonatal}

O teste do pezinho baseia-se em um exame de triagem para o rastreamento de doenças em recém-nascidos como, por exemplo: a fenilcetonúria, o hipotireoidismo congênito, doenças falciformes e outras hemoglobinopatias, e a fibrose cística, sendo um exame disponibilizado pelo SUS com função realizar o encaminhamento e acompanhamento clínico, de exames complementares e tratamentos existentes, para o RN identificado com alguma das doenças citadas acima e com finalidade de fazer diagnóstico precoce de patologias congênitas do metabolismo e o surgimento de ações de $\mathrm{TN}$ em fase pré-sintomática, de forma a precaver o aparecimento de retardo metal e outras complicações através de tratamentos e acompanhamentos adequados (VESPOLI et al., 2011).

O Programa Nacional de Triagem Neonatal constitui-se de três frases, sendo que cabe a cada estado um nível diferente de organização. No Brasil, são poucos os estados que oferecem o rastreamento de fase três na qual identifica as quatro doenças (LEITE; PONTES, 2009).

\section{Atualizações e informações gerais acerca do Teste do Pezinho}

No dia 14 de dezembro 2012, por meio da portaria de n² 2.829, o Ministério da Saúde implantou a fase IV do PNTN com o rastreamento de duas novas doenças identificadas através 
do "teste do pezinho". Sendo a deficiência de biotinidase e a hiperplasia adrenal congênita. Os Estados que desejarem se habilitar na fase IV do PNTN, devem comunicar à Secretaria de Atenção à Saúde por meio de um ofício no qual será solicitada a autorização para a habilitação, onde serão seguidos critérios estabelecidos pelo Ministério da Saúde (BRASIL, 2012).

O principal objetivo do Programa Nacional de Triagem Neonatal é aumentar o número das patologias triadas para $100 \%$ dos nascidos vivos. E para isso, almeja inserir as esferas municipal, estadual e federal, com o intuito de consolidar e padronizar o atendimento ofertado pelos Serviços de Referência em Triagem Neonatal (SRTN) credenciados. A finalidade do PNTN é criar um banco de dados que permita avaliar como estão sendo o funcionamento do programa no Brasil e suas regiões e desta forma, orientar posteriores trabalhos (GARCIA; FERREIRA; OLIVEIRA, 2007).

As unidades de saúde devem possuir pelo menos dois funcionários treinados para a coleta do TP, podendo ser uma enfermeira ou uma técnica de enfermagem. Dessa forma, é feita uma capacitação com estes profissionais na unidade distrital de referência da unidade básica, totalizando uma carga horária entre seis a oito horas. Após a capacitação é feita uma reunião com toda a equipe da unidade de saúde (médicos, enfermeiras, auxiliares e técnicos de enfermagem, agentes administrativos, etc.), tendo como finalidade, passar as informações pertinentes em relação ao teste do pezinho, explicando a importância da sua coleta (PASQUALIN, 2006).

Também é de extrema importância enfatizar, conforme Brasil (2008) que a realização do "teste do pezinho" não deve ser feita no recém-nascido com menos de 48 horas de vida do mesmo, pois podem ocorrer alterações no resultado do exame como diagnóstico falso-positivo para algumas patologias como, por exemplo, a fenilcetonúria e hipotireoidismo congênito, dessa forma, aconselha-se que o RN tenha mamado para que a fenilalanina se acumule na corrente sanguínea. E no caso do hipotireoidismo, logo após o nascimento do bebê ocorre à liberação de TSH na corrente sanguínea, diminuindo assim as concentrações de TSH. 


\section{Principais Patologias Identificadas por meio do Teste do Pezinho}

\section{Fenilcetonúria}

A fenilcetonúria foi inicialmente identificada em 1934 pelo químico norueguês Asbjorn Fölling, por meio do relato de dois irmãos acometidos por essa patologia, e que apresentavam quadro clínico de retardo mental relacionado ao achado de eliminação urinária de ácido fenilpirúvico e fenilacético, tendo sido este o primeiro caso de erro inato do metabolismo a ser oficialmente associado à presença de deficiência mental (AMORIM et al., 2005).

Esta doença trata-se de um erro inato do metabolismo do aminoácido fenilalanina (FAL), ela ocorre devido uma mutação no gene responsável por codificar a enzima fenilalanina hidroxilase. Esta enzima é ativada no fígado e responsável em converter a fenilalanina em tirosina. Esse processo faz com que tenha um aumento nos níveis de fenilalanina na corrente sanguínea permitindo então seu acúmulo no sistema nervoso central (SNC), resultante em efeito tóxico ao RN (STRANIERI; TAKANO, 2009).

Elevadas concentrações de fenilalanina no sangue acionam vias secundárias do metabolismo da fenilalanina, resultando então na elevação da produção de fenilcetonas e outros produtos metabólicos, que são ligeiramente filtrados pelos rins e eliminados pela urina. A fenilcetonúria quando não tratada ocasiona em grave retardamento mental. Crianças que são acometidas por esta patologia aparentam inicialmente normais ao nascer e os primeiros sintomas são geralmente imperceptíveis como, por exemplo, a dificuldade em se alimentar, vômitos e retardamento no desenvolvimento da mesma (MATTOZO; SOUZA, 2005).

Pacientes com fenilcetonúria podem evidenciar sintomas mais brandos, desde a deficiência de pigmentação, como também sintomas extremamente mais graves, como por exemplo, o transtorno de conduta e o retardamento mental. Estudos mostraram que para cada 10 semanas de retardamento no tratamento do paciente com fenilcetonúria através da redução da fenilalanina, o mesmo apresenta perda acentuada de cerca de 5 unidades de QI (quociente de inteligência) (VESPOLI et al., 2011).

Outros fatores que também ocasionam a elevação da fenilalanina estão à prematuridade da criança, doenças nos rins ou fígado, como também o uso de medicações quimioterápicas Já os danos cerebrais começam por volta da $3^{\mathrm{a}}$ semana de vida do RN e acentua-se por volta do $8^{\circ}$ mês de vida. Quando o tratamento não é realizado, a fenilcetonúria desenvolve- se de forma 
rápida e irreversível para o retardamento mental. Mesmo que o diagnóstico do RN seja tardio (entre o quarto ou sexto mês de vida), é conveniente a realização da terapia dietética, pois diminui a deterioração mental (MATTOZO; SOUZA, 2005).

A fenilcetonúria pode se apresentar de três formas e sua classificação será de acordo com seu percentual enzimático encontrado (SILVA, 2008). Aconselha-se que a coleta de sangue para o diagnóstico desta deve ser feita no quinto dia de vida, tempo que a criança já tenha recebido alimentação com o leite, pois deve ter ingestão de proteínas até o quinto dia de vida do recém-nascido, para avaliar com maior segurança o metabolismo da fenilalanina pelo fígado se está normal ou não. Se o sangue for coletado antes do quinto dia, o exame pode falsamente parecer normal, podendo ocorrer assim o risco de detectar tardiamente uma criança afetada, cujo teste do pezinho apresentou resultados de normalidades no nascimento (SILVA, 2012).

Deve-se também manter uma atenção especial mais voltada para as meninas que apresentam Hiperfenilalaninemia permanente, pois, durante a gestação, os níveis de FAL materna apresentam-se elevados e isto propicia a maior incidência de deficiência mental (cerca de $21 \%$ ), baixo peso ao nascer (cerca de $13 \%$ ) e microcefalia (cerca de $24 \%$ ). Estas meninas, em período de idade fértil, devem estar sendo aconselhadas a iniciarem a dieta para pacientes com fenilcetonúria e com isso conservar níveis mais baixos ou iguais a $4 \mathrm{mg} / \mathrm{dl}$ antes de engravidarem, e manter assim por todo período da gestação (SILVA, 2008).

O tratamento é feito através da restrição de fenilalanina na dieta da criança, com suplementação de tirosina, sendo que esta dieta deve ser obrigatoriamente supervisionada e elaborada por uma nutricionista, além de que a mesma deve monitorar as dosagens seriadas da fenilalanina na corrente sanguínea. O objetivo deste tratamento é preventivo e deve ser iniciado o mais cedo possível, devendo ser mantido por toda a vida do indivíduo (SILVA, 2012).

\section{Hipotireoidismo Congênito}

É uma doença hereditária do metabolismo, na qual impede o desenvolvimento do hormônio tireoidiano T4, sendo este o responsável pelo crescimento e amadurecimento de todo o organismo, principalmente a maturação do cérebro. Estima-se que apenas $5 \%$ das crianças ao nascerem apresentaram algum tipo de sintoma, dificultando assim o diagnóstico precoce para a 
doença e fazendo com que por muito tempo, o hipotireoidismo congênito fosse uma das principais causas de retardo mental no Brasil e no mundo (VESPOLI et al., 2011).

O hipotireoidismo congênito pode ser classificado como primário (quando a falha ocorre na glândula tireóide), secundário (quando ocorre deficiência de TSH hipofisário), terciário (quando ocorre deficiência de TRH hipotalâmico) e resistência periférica à ação dos hormônios tireoidianos (SILVA, 2012).

Existem variantes para a incidência do HC, que podem ser desde raça, sexo e níveis de iodo presentes na dieta do indivíduo, chegando a 1:2300 a 1:5000 para os nascidos brancos e 1:3500 para os nascidos negros. Entretanto, nas regiões onde existe maior deficiência de iodo, estes dados podem chegar até 1:200, devido à miscigenação no Brasil. Deve também levar em consideração que estes valores podem variar ainda mais se forem considerados como, por exemplo, números do Censo 2000, onde $45,3 \%$ da população brasileira foram consideradas da cor preta ou parda (VESPOLI et al., 2011).

Os hormônios T3 e T4 representam extrema importância para a formação protéica; para o metabolismo dos lipídios e dos carboidratos; para o desenvolvimento físico e do (SNC) sistema nervoso central; força e integridade muscular, sendo este sob o controle do TSH (hormônio estimulante de tiroxina), que por sua vez é estimulado pelo TRH (hormônio liberador de TSH) e em seguida é eliminado pelo hipotálamo, e desativado pelos hormônios tireoidianos. A forma de apresentação do $\mathrm{HC}$ na criança pode ser tanto na forma assintomática, como também evidenciar uma forma clínica clássica (REICHERT; PACÍFICO, 2003).

O tratamento é feito através da administração de doses únicas e diárias T4 e avaliar periodicamente os níveis hormonais no indivíduo com a doença, para saber se estes níveis estão normais e estabilizados (MATTOZO; SOUZA, 2005).

\section{Anemia Falciforme e outras Hemoglobinopatias}

As hemoglobinopatias são divididas em dois grupos, no primeiro são as alterações resultantes em anormalidade estrutural em uma das cadeias da globina. Já o segundo grupo encontram-se as talassemias, na qual ocorre uma redução na velocidade de produção de cadeias de globina ou impossibilidade genética em produzir tal cadeia. A anemia falciforme é o distúrbio que ocorre com maior frequência entre as hemoglobinopatias, sendo esta caracterizada 
pela disposição das hemácias, quando em condições de baixo nível de oxigênio, adquirirem uma forma anormal (forma de foice). Os indivíduos afetados comumente apresentam anemia na infância, evidenciado por níveis de hemoglobina de 6 a $10 \mathrm{mg} / \mathrm{dl}$, assim como atraso no desenvolvimento, a esplenomegalia e infecções recorrentes (SILVA, 2012).

Os portadores do traço falciforme tem maior predisposição em desenvolver fenômenos vasooclusivos, que são os principais responsáveis pelos sintomas apresentados pelos homozigotos. As manifestações clínicas podem variar, sendo assintomáticas nos primeiros seis meses de vida do portador da doença devido à presença de hemoglobina fetal ( $\mathrm{Hbf})$, como também sintomáticas, evidenciados por quadros de crises dolorosas, síndrome torácica aguda, AVC, úlceras de pernas e anemia hemolítica (MENDONÇA et al., 2008).

O diagnóstico da anemia falciforme e outras hemoglobinopatias é feito de forma simplificada e barata, uma vez que os meios utilizados para o rastreamento destas patologias são através da cromatografia líquida de alta performance (HPLC) ou pela ligação isoelétrica. Após este processo de rastreamento, é feito outro exame que irá constatar a positividade das patologias que é a eletroforese de hemoglobina, onde é coletada amostra sanguínea total do paciente. Quando a anemia falciforme ou outras hemoglobinopatias não são diagnosticadas na $\mathrm{TN}$, pode acontecer o surgimento de sintomas como a irritabilidade, anemia hemolítica entre 8 a 10 semanas de vida, febre, dactilite (síndrome mão-pé), infecções e esplenomegalia. O ápice da morbimortalidade ocorre entre 2 a 3 anos de vida, sendo que as principais causas de óbito são devido a processos de sepse, choque e anemia profunda por isso, aconselha-se que o início do tratamento ocorra antes dos 4 meses de vida, pois evita que os processos infecciosos ou outras complicações ocasionem a morte do bebê (SILVA, 2008).

O tratamento baseia-se na administração de antibióticos a partir dos quatro meses de vida da criança. Também é indicado que se faça a vacina antipneumocócica conjugada 7 com esquema de 2, 4 e 6 meses de idade e reforço entre 12 e 15 meses de idade. Além das vacinas contra o Haemophilus influenzae tipo b e contra meningite tipo $\mathrm{C}$ conjugada (MENDONÇA, et al., 2008).

Dessa forma, a portaria de $n^{\circ} 1.391$ de 16 de agosto de 2005 , tem como objetivo primordial, mudar o curso natural dessas patologias, promovendo assim a diminuição da morbimortalidade e consequentemente, garantir uma melhor qualidade de vida aos mesmos (SILVA, 2008). 


\section{Fibrose cística}

A FC é um tipo de distúrbio de herança genética, que afeta cerca de 1:2.500 recémnascidos e tem maior incidência em pessoas da cor branca (NETO, 2005 apud SILVA, 2008). Esta patologia apresenta grande nível letalidade, atingindo principalmente pulmões e pâncreas, ocasionando processo obstrutivo devido aumento da viscosidade de muco. Nos pulmões, o aumento do muco propicia uma maior incidência de proliferação bacteriana, lesão pulmonar e consequentemente o óbito através da disfunção respiratória. No pâncreas, o acúmulo do muco leva a destruição dos ductos, fazendo com que tenha perda acentuada de enzimas digestivas, ocasionando em má nutrição (SILVA, 2008).

Os sintomas mais evidentes são atraso no crescimento, dificuldade respiratória, infecções respiratórias, insuficiência cardiorrespiratória, expectoração exacerbada com presença de muco, tosse, perda de peso acentuada, pele cianótica, perda de sal pelo suor (denominado de beijo salgado) e diminuição da capacidade reprodutora (VESPOLI et al., 2011).

O diagnóstico precoce para esta doença é feito através da TN, onde realiza a dosagem de tripsina imunorreativa (IRT). Já o diagnóstico confirmatório é feito pelo teste do suor, onde é feita a dosagem da quantidade de sódio e cloro presente na corrente sanguínea, assim como por biologia molecular. Enfim, o tratamento baseia-se em melhorar a qualidade de vida do paciente, por meio de antibióticos, vacinação, fisioterapia, acompanhamento nutricional e uso de enzimas pancreáticas para os quadros digestivos (SILVA, 2012).

\section{Técnica para a Coleta das Amostras}

A coleta da amostra de sangue do $\mathrm{RN}$ deve ser feita com pelo menos 72 horas de vida do mesmo, recomenda-se também que o RN já tenha iniciado sua alimentação com leite materno. O primordial para a coleta do teste, é que seja feito nos primeiros sete dias de vida e que nunca ultrapasse os três meses, exceto se não houver indicação específica. Em situações onde o RN for prematuro, deve-se avisar a genitora que uma nova coleta sanguínea deverá ser 
feita após 30 dias da coleta da primeira amostra de sangue. É importante esclarecer para a mãe que os exames colhidos com menos de 72 horas não serão efetivados (PASQUALIN, 2006).

As coletas das amostras de sague podem ser realizadas em postos ou centros de saúde, hospitais e maternidades (MATTOZO; SOUZA, 2005). É necessário que seja realizado o preenchimento completo do cartão com caneta esferográfica e que os dados estejam legíveis (MÜLLER, 2012).

Nos postos de coleta, são feitas fichas cadastrais dos RN's, onde devem conter todos seus dados de identificação. É necessário que a mãe forneça todas as informações necessárias de forma clara e objetiva, informando principalmente seu endereço, pois se houver alguma alteração no resultado a família deve ser imediatamente comunicada (AMORIM, 2005).

A realização do teste deve ser feita em ambiente tranquilo e sem umidade, para que os indivíduos envolvidos sintam-se mais a vontade e assim, fazer com que o exame seja bem sucedido (SILVA, 2012).

Recomenda-se o aquecimento do pezinho do bebê por fricção do calcanhar, porém, quando está muito frio só a fricção não atingirá o aquecimento desejado, assim, pode ser utilizada bolsa de água morna. Antes de realizar o teste, o profissional orienta o responsável sobre a forma adequada de segurar o bebê (posição de arroto) no momento da coleta: em pé, apoiando com firmeza sobre o ombro, permitindo que as pernas e os pés do bebê fiquem livres (GARCIA; FERREIRA; OLIVEIRA, 2007).

Ao término do preenchimento das fichas de identificação, é realizada a punção no pé do bebê para obtenção das amostras de sangue. E para a coleta, é imprescindível que, todo o material necessário que será utilizado na punção do pé do $\mathrm{RN}$ deve ser descartado após o procedimento. Vale ressaltar que todos os procedimentos utilizados para a coleta do teste são feitos de acordo normas padronizadas (SILVA, 2012).

O teste é feito através do furinho em uma das regiões laterais do pé do $\mathrm{RN}$ para a obtenção das gotinhas de sangue.. Este procedimento é feito desta forma para evitar atingir o osso do calcanhar (ALVES; ZAMBRANO, 2011).

Em hipótese alguma se recomenda pressionar o calcâneo do bebê, pois este procedimento pode ocasionar hemólise e extravasamento de líquido intersticial. A conduta adequada é de aguardar a formação de uma gota espessa do sangue e em seguida encostá-la no verso do primeiro círculo do papel filtro. É importante ressaltar que se faz necessário esperar o 
sangue fluir de forma espontânea e com isso evitar realizar a "ordenha", pois esta manobra permite a liberação de plasma do tecido, diluindo assim a amostra colhida e em seguida, preencher os círculos do papel filtro com sangue (PASQUALIN, 2006). Após a coleta do sangue, deve pressionar a área que foi puncionada com um algodão limpo ou fixar uma bandagem antisséptica no local (MATOZZO; SOUZA, 2005).

O sangue coletado no papel filtro deve ser submetido a um processo de secagem por pelo menos duas horas em temperatura ambiente, em seguida, deve envolvê-lo em sacos plásticos específicos, de acordo a orientação de cada laboratório. O laboratório responsabilizase por enviar os resultados ao posto onde foram coletadas as amostras e este disponibiliza a família que irá apresentá-lo ao pediatra que acompanha o bebê. Em casos de exames com diagnóstico suspeito, o laboratório comunica o posto de coleta para que este entre em contato com as famílias solicitando a presença do bebê para a realização de novos exames confirmatórios (AMORIM, 2005).

É importante que se evite o ressecamento excessivo das amostras e guardá-las após a secagem, na geladeira, dentro de um saco plástico bem fechado, protegendo contra a umidade. Em hipótese alguma deve ocorrer contato da amostra durante a coleta com algum líquido estranho, nem mesmo álcool, ou água, evitando assim a diluição ou hemólise do sangue colhido. O formulário completo do paciente deve ser enviado para o laboratório no máximo em 24 horas após a coleta do material (MATOZZO; SOUZA, 2005).

\section{O papel do Enfermeiro na Orientação do Teste do Pezinho}

O enfermeiro (a) representa um importante e imprescindível papel quanto a sua participação no PNTN, devido o seu maior contato com a gestante e sua família. Pois desde o pré-natal, o profissional deve passar todas as informações pertinentes a gestante para que após o nascimento e alta hospitalar do $\mathrm{RN}$, a mesma deverá levá-lo para realizar o teste do pezinho, onde serão coletadas amostras de sangue do RN, com objetivo de prevenir doenças como o retardo mental e enfatizar que o exame é totalmente gratuito, exigido por lei e fornecido pelo SUS (SILVA, 2012). 
Para que haja o processo de prevenção em saúde, é necessário que o público alvo tenha certo conhecimento sobre como ocorre o ato de prevenir. O teste do pezinho é um dos exames de detecção precoce de doenças relacionadas aos RN's. A equipe de enfermagem que lida diretamente na realização desse exame deve-se manter informada por meio de programas voltados a saúde sobre a realização da coleta dentro do PNTN. Os profissionais que irão ter contato direto com os pais no período do nascimento do bebê, devem passar todas as informações pertinentes sobre o teste do pezinho, pois estas informações passadas fazem com que aumente a probabilidade destes pais entenderem a importância da triagem neonatal e consequentemente levarem seus filhos para realizarem o TP no tempo certo (GARCIA; FERREIRA; OLIVEIRA, 2007).

A técnica de coleta das amostras sanguíneas para o TP é um procedimento da enfermagem e dessa forma, este deve ter em mente o que e porque estará realizando o teste. Deve preencher de forma correta a ficha de coleta, pois é nela que se encontram todas as informações pertinentes sobre o RN, e, se por ventura ocorrer à reconvocação do bebê para nova coleta seja por produto modificado ou erro técnico, a busca ativa da genitora será mais eficiente. O enfermeiro deve também promover amparo psicológico para a mãe ou responsável e permitir sua participação no momento da coleta com o objetivo de tranquilizá-la, e também de mostrar a importância da realização do teste do pezinho (SILVA, 2012).

O enfermeiro (a) representa um importante e imprescindível papel quanto a sua participação no PNTN, devido o seu maior contato com a gestante e sua família. Pois desde o pré-natal, o profissional deve passar todas as informações pertinentes a gestante para que após o nascimento e alta hospitalar do RN, a mesma deverá levá-lo para realizar o teste do pezinho, onde serão coletadas amostras de sangue do RN, com objetivo de prevenir doenças como o retardo mental e enfatizar que o exame é totalmente gratuito, exigido por lei e fornecido pelo SUS (SILVA, 2012).

\section{Considerações Finais}

A triagem neonatal, popularmente conhecida como teste do pezinho é um exame gratuito, oferecido pelo SUS e tem como objetivo rastrear doenças do metabolismo em recém- 
nascidos e dessa forma identificá-las precocemente, evitando assim possíveis complicações decorrentes dessas patologias.

Os primeiros estudos da Triagem neonatal tiveram início na década de 50 e até os dias atuais observamos que ainda existem buscas pelo aperfeiçoamento e ampliação da cobertura das doenças rastreadas pelo teste de triagem neonatal. O Ministério da Saúde em parceria com as equipes de saúde buscam enfatizar a importância da realização precoce do teste do pezinho, com o intuito de melhorar a qualidade de vida dessas crianças e consequentemente, reduzir os níveis de morbimortalidade.

De modo geral, verificamos que existe ainda uma falha na orientação durante o pré-natal por parte dos profissionais de saúde que lidam diretamente com as gestantes, uma vez que metade dessas mulheres informaram que não foram instruídas no pré-natal quanto a importância de se realizar o teste do pezinho. E como consequência, verificasse que estas mulheres não compreendem a real importância em se realizar o teste do pezinho nos recém-nascidos, que é o diagnóstico precoce de doenças do metabolismo para tratá-las o mais cedo possível, reduzindo os danos para estas crianças.

Dessa forma, os profissionais de saúde irão conseguir prestar todos os esclarecimentos pertinentes ao teste e que consequentemente levarão a estas gestantes um maior nível de conhecimento quanto à importância da realização precoce do teste do pezinho em recémnascidos, e o enfermeiro tem papel crucial nesta demanda, atuando em prol da melhor orientação para que o teste seja feito da forma mais eficiente e correta possível.

\section{Referências}

ALMEIDA, A. M. et al. Avaliação do Programa de Triagem Neonatal na Bahia no ano de 2003. Revista Brasileira de Saúde Materno Infantil, v.6, n.1, p.85-91, Bahia, 2006.

ALVES, N.; ZAMBRANO, E. Teste do Pezinho: A Opinião das Mães sobre a Realização do Exame Concomitante a Amamentação. Anuário da Produção de Iniciação Científica Discente, v.13, n.17, p.115-133, São Paulo-SP, 2011.

AMORIM, J. F.; SOUZA, M. H. N. O Conhecimento das Mães Acerca da Triagem Neonatal. Revista de Enfermagem UERJ, v.13, n. , p. 27-31, Rio de Janeiro- RJ, 2005. 
AMORIM, T. et al. Aspectos Clínicos da Fenilcetonúria Em Serviço De Referência Em Triagem Neonatal Da Bahia. Revista Brasileira de Saúde Materno Infantil, v.5, n.4, p.457462, Recife-PE, 2005.

BRASIL. Conselho Nacional de Saúde. Resolução no 196 de 10 de Outubro de 1996. BrasiliaDF, $1996 . \quad$ Disponível em: <http:// http://dtr2004.saude.gov.br/susdeaz/legislacao/arquivo/Resolucao_196_de_10_10_1996.pdf>. Acessado em 10 de abril de 2017.

Ministério da Saúde. Manual de Normas Técnicas e Rotinas Operacionais do Programa Nacional de Triagem Neonatal. $1^{\mathrm{a}}$ ed. Brasília- DF, 2002. Disponível em: <http://www.http://bvsms.saude.gov.br/bvs/publicacoes/triagem_neonatal.pdf $>$. Acessado em: 15 de abril de 2017.

Ministério da Saúde. Secretaria de Ciência, Tecnologia e Insumos Estratégicos. Biotina para o Tratamento da Deficiência de Biotinidase. Brasília-DF, 2012. Disponível em: <ttp://portal.saude.gov.br/portal/arquivos/pdf/Relatorio_Biotina_Defic_Biotinidase_CP.pdf >. Acessado em 25 de março de 2017.

Ministério da Saúde. Portaria GM/MS nº 822/GM Em 06 de junho de 2001.

Brasília- DF, 2001. Disponível em:
<http://www.dtr2001.saude.gov.br/sas/PORTARIAS/Port2001/GM/GM-822.htm>. Acessado em 10 de março de 2017.

. Ministério da Saúde. Portaria GM/MS n 2.829, de 14 de dezembro de 2012. BrasíliaDF, 2012. Disponível em: <http://bvsms.saude.gov.br/bvs/saudelegis/gm/2012 /prt2829_14_12_2012.html>. Acessado em 09 de abril de 2017

GARCIA, M. G.; FERREIRA, E. A. P.; OLIVEIRA, F. P. S. Análise da Compreensão de Pais Acerca do Teste do Pezinho Revista Brasileira de Crescimento e Desenvolvimento Humano, v.17, n.1, p.01-12, Belém, 2007.

GIL, A. C. Como elaborar um projeto de pesquisa. 11ª Ed: São Paulo: Atlas, 2009.

LEITE, V. M.; PONTES, D. B. S. A Evolução da Triagem Neonatal no Brasil. Departamento de Enfermagem - Faculdades Integradas de Ourinhos- FIO-FEMM. Ourinhos- SP, 2009. Disponível em: <http://www.fio.edu.br/cic/anais/2009_viii_cic/Artigos/07/07.12.pdf>. Acessado em: 02 de maio de 2017.

MATTOZO, M.; SOUZA, L. C. Triagem Neonatal Em Santa Catarina: Relato Histórico, Aspetos Fisiopatológicos E Métodos De Análise Realizados Pelo Laboratório Central Da Secretaria De Saúde Do Estado. News Lab, ed.68, p.84-102, Florianópolis-SC, 2005. Disponível em: <http://www.newslab.com.br/ed_anteriores/68/art06.pdf >. Acessado em 16 de maio de 2017. 
MÜLLER, Hospital Universitário Júlio. Manual De Procedimentos Para Postos De Coleta Do Teste Do Pezinho. Serviço de Referência em Triagem Neonatal do Estado de Mato Grosso. Cuiabá-MT, 2012. Disponível em: $<$ http://200.17.60.3/ufmt/site/userfiles/Manual\%20do\%20pezinho\%282\%29.pdf>. Acessado em 26 de maio 2017.

MENDONÇA, A. C. et al. Muito Além Do "Teste Do Pezinho ". Revista Brasileira De Hematologia E Hemoterapia, v.31, n.2, p.88-93, Marília-SP, 2008.

PASQUALIN, L. Manual de Procedimentos para Postos Municipais de Coleta do Teste do Pezinho. Ribeirão Preto- SP, 2006. Disponível em: < http://200.17.60.3/ufmt/site/userfiles/Manual\%20do\%20pezinho\%282\%29.pdf >. Acessado em 15 de mar 2017.

REICHERT, A. S.; PACÍFICO, V. C. Conhecimento De Mães Quanto A Importância Do Teste Do Pezinho. Revista Brasileira de Enfermagem, v.56, n.3, p.226-229, Brasília-DF, 2003.

RODRIGUES, D. O. W. et al. Diagnóstico Histórico Da Triagem Neonatal Para Doença Falciforme. Revista APS, v.13, n.1, p.34-45, Juiz de Fora- MG, 2010.

SANTOS, E. C. et al. O Conhecimento de Puérperas sobre a Triagem Neonatal. Revista Cogitare de Enfermagem, v.16, n.2, p.282-288, Cuiabá-MT, 2011.

SALLES, M.; SANTOS, I. M. M. O Conhecimento Das Mães Acerca Do Teste Do Pezinho Em Uma Unidade Básica De Saúde. Revista De Pesquisa: Cuidado É Fundamental, v.1, n.1, p.59-64, Rio de Janeiro-RJ, 2009.

SILVEIRA, M. T. et al., Hiperplasia Adrenal Congênita: Estudo Qualitativo sobre Doença e Tratamento, Dúvidas, Angústias e Relacionamentos (parte I). Revista Brasileira de Endocrinologia e Metabologia, v.53, n.9, p. 1112-1124, São Paulo -SP, 2009.

SILVA, C. S. Conhecimento Das Mães E Do Enfermeiro Acerca Da Triagem Neonatal. Porto Alegre- 2008.2 DS, Disponível <http://www.lume.ufrgs.brbitstreamhandle1018316269000668989.pdfsequence=1. pdf . Acessado em 10 de abril de 2017.

SILVA, T. S. Nível De Conhecimento Das Puérperas Sobre A Importância Da Realização Do Teste Do Pezinho Em Um PSF No Município De Caculé - Ba. Vitória da Conquista- BA, 2012.

STRANIERI, I.; TAKANO, O. A. Avaliação do Serviço de Referência em Triagem Neonatal para hipotireoidismo congênito e fenilcetonúria no Estado de Mato Grosso, Brasil. Arquivo Brasileiro de Endocrinologia e Metabologia, v.53, n.4, p.446-452, Cuiabá-MT, 2009. 
VESPOLI, S. et al. Análise das Prevalências de Doenças Detectadas pelo Programa Nacional de Triagem Neonatal no Município de Araraquara no Ano de 2009. Revista de Ciências e Farmácia Básica Aplicada, v.32, n.2, p.269-273, Araraquara-SP, 2011.

\section{Como citar este artigo (Formato ABNT):}

OLIVEIRA, Eva F.; SOUZA, Anderson P. A Importância da Realização Precoce do Teste do Pezinho: O Papel do Enfermeiro na Orientação da Triagem Neonatal. Id On Line Revista Multidisciplinar e de Psicologia, Maio de 2017, VOL.11, N.35, P. 361-378. ISSN: 1981-1179.

Recebido: 27.05.2017

Aceito: 27.05.2017 